\title{
Thermal inactivation kinetics of Aspergillus oryzae $\beta$-galactosidase in concentrated lactose solution
}

\author{
Viera Illeová, Milan Polakovič \\ Department of Chemical and Biochemical Engineering, \\ Institute of Chemical and Environmental Engineering, Faculty of Chemical and Food Technology, \\ Slovak University of Technology,Radlinského 9, 81237 Bratislava, Slovakia \\ milan.polakovic@stuba.sk
}

\begin{abstract}
Thermal inactivation of a commercial $\beta$-galactosidase from Aspergillus oryzae in a $300 \mathrm{~g} / \mathrm{L}$ lactose solution was studied in the temperature range of $65-75^{\circ} \mathrm{C}$. Lactose exhibited a stabilisation effect when similar inactivation rates as those in lactose solution were observed in a lactose-free solution at temperatures lower by $5{ }^{\circ} \mathrm{C}$. Inactivation process in the lactose solution was biphasic. A kinetic model based on the Lumry-Eyring mechanism was proposed and successfully verified. Estimated activation energy values were very different. Rather high activation energy values of the forward reactions were responsible for both the significant change of rate constants and the rate-controlling reaction with temperature. For these two reasons, an increase of the operational lifetime of the enzyme from 7 days at $60{ }^{\circ} \mathrm{C}$ to 580 days at $55^{\circ} \mathrm{C}$ was predicted.
\end{abstract}

Keywords: $\beta$-galactosidase, thermal inactivation, kinetics, Lumry-Eyring mechanism, multitemperature modelling

\section{Introduction}

$\beta$-Galactosidase ( $\beta$-GAL) is an enzyme with several important industrial applications. One of them is the production of lactose-free dairy products for people with lactose intolerance. Other applications that exploit the hydrolytic activity of $\beta$-GAL toward lactose include industrial processing of whey for ethanol production or dairy wastewater processing. Finally, prebiotic compounds, galactooligosaccharides (GOS), are also produced from concentrated lactose solutions using the transgalactosylation activity of $\beta$-GAL.

Elevated temperature is beneficial in all these enzymatic processes since it results in increased reaction rate and bioreactor productivity. It offers additional advantages for the production of GOS, increases lactose solubility and decreases the viscosity of reaction medium. Since $\beta$-GAL, as each enzyme is a thermolabile compound, the reaction temperature has to be strictly optimised to find a compromise between good activity and stability.

Thermal stability of $\beta$-GAL in its free or immobilised form has been investigated by a number of authors. Its stability varies significantly among different microbial producers of the enzyme. Flaschel (2006) studied the stability of three different $\beta$-GAL forms during UHT milk lactose hydrolysis. He found that $K$. lactis $\beta$-GAL is the most thermolabile form which is sufficiently stable only below $40{ }^{\circ} \mathrm{C}$. Enzymes from A. oryzae and E. coli are stable up to $50{ }^{\circ} \mathrm{C}$. Osman et al. (2014) studied the stability of E. coli $\beta$-GAL during the production of GOS and found that a complete conversion can be achieved at the temperature of $55^{\circ} \mathrm{C}$.

$K$. marxianus $\beta$-GAL preparations have sufficient stability in a phosphate buffer solution only at temperatures below $40{ }^{\circ} \mathrm{C}$ (Braga et al., 2013).

A similar observation was made by Ladero et al. (2006) for a commercial $K$. fragilis $\beta$-GAL. The stability of purified preparations was however several times higher than that of their crude counterparts. $B$. circulans $\beta$-GAL has a half-live of only about $5 \mathrm{~min}$ at $60^{\circ} \mathrm{C}$ which increased to $4 \mathrm{~h}$ for an immobilised form of this enzyme (Urrutia et al., 2013). Nakanishi et al. (1983) presented the half-lives of 50 days at $50{ }^{\circ} \mathrm{C}$ and 15 days at $55^{\circ} \mathrm{C}$ for an immobilised form of $B$. circulans $\beta$-GAL. Specific results were achieved for highly thermostable $\beta$-GAL from Thermus sp. which has a half-life of about $1 \mathrm{~h}$ at $90{ }^{\circ} \mathrm{C}$ and can withstand temperatures close to the solution boiling point for a short period of time (Ladero et al., 2005; Ladero et al., 2006).

The objective of this work was to investigate the inactivation of a commercial $\beta$-GAL from A. oryzae in a concentrated lactose solution at different temperatures and to determine a suitable inactivation mechanism. The resulting time-activity data were processed using the so-called multitemperature evaluation method (Vrábel et al., 1997; Polakovič and Bryjak, 2002), which can be successfully described by a complex inactivation model (Illeová et al., 2003).

Inactivation experiments were carried out also in a lactose-free solution to determine the stabilisation effect of this saccharide. 


\section{Materials and methods}

\section{Materials}

B-GAL powder Tegaferm LAC A100P from A. oryzae with estimated initial activity of $100000 \mathrm{U} \mathrm{g}^{-1}$ was purchased from Tegaferm Holding GmbH (Wien, Austria). Lactose monohydrate was obtained from Centralchem (Bratislava, Slovakia), o-nitrophenyl$\beta$-D-galactopyranoside (ONPG) and 2-nitrophenol were provided by Sigma-Aldrich (St. Louis, USA). All other reagents were of analytical grade and were obtained from Mikrochem (Pezinok, Slovakia). Acetate buffer was prepared from $0.1 \mathrm{M}$ acetic acid and adjusted to $\mathrm{pH} 4.5 \mathrm{using} 0.1 \mathrm{M}$ sodium acetate. Enzyme stock solution in the acetate buffer was prepared at the $\beta-\mathrm{GAL}$ concentration of $3 \mathrm{~g} / \mathrm{L}$.

\section{Inactivation experiments}

Enzyme inactivation experiments were carried out either in a reaction medium with the initial lactose concentration of $300 \mathrm{~g} / \mathrm{L}$ or in the lactose-free acetate buffer. The temperature range used was $65-75^{\circ} \mathrm{C}$. About $15 \mathrm{~mL}$ of the liquid was preheated to the inactivation temperature and $1 \mathrm{~mL}$ of the enzyme stock solution was added. Sampling frequency was adjusted to the dynamics of the inactivation process. The sample volume was $0.7 \mathrm{~mL}$. Enzyme inactivation was stopped by cooling the samples in ice water.

\section{Determination of enzyme activity}

Residual activity of enzyme samples was measured at $37^{\circ} \mathrm{C}$ using the initial rate method when a $3.7 \mathrm{~g} / \mathrm{L}$ ONPG solution in the acetate buffer was used as the substrate. The enzymatic reaction was stopped by adding $10 \%$ sodium carbonate. The concentration of 2-nitrophenol released was determined using a UV-Vis spectrophotometer at the wavelength of $420 \mathrm{~nm}$. One unit of $\beta$-GAL activity corresponded to 1 micromole of 2-nitrophenol produced from ONPG by $\beta$-GAL per minute.

\section{Mathematical modelling}

In this study, a kinetic model (Onderková et al., 2010) was examined for the description of the courses of relative enzyme activity, $a$, defined as the ratio of $c_{\mathrm{N}}$, the concentration of native enzyme form, $\mathrm{N}$, in time, $t$, and $c_{\mathrm{N} 0}$, its initial concentration. This model was based on the mechanism:

$$
\mathrm{N} \underset{k_{-1}}{\stackrel{k_{+1}}{\rightleftarrows}} \mathrm{R} \stackrel{k_{2}}{\longrightarrow} \mathrm{I}
$$

where $\mathrm{N}$ undergoes a reversible transformation into the intermediate inactive form, $\mathrm{R}$, which then reacts irreversibly to the inactive form, I. Symbols $k_{+1}, k_{-1}$, and $k_{2}$ are the rate constants of individual reactions. The mechanism has the same form as the well-known mechanism of Lumry-Eyring (1954) but the interpretation is different. In the Lumry-Eyring mechanism, the intermediate is considered to be a fully unfolded enzyme and rapid equilibrium is typically assumed for the first reaction.

The inactivation process was described by a set of the following differential equations:

$$
\begin{gathered}
\frac{\mathrm{d} c_{\mathrm{N}}}{\mathrm{d} t}=-k_{+1} c_{\mathrm{N}}+k_{-1} c_{\mathrm{R}} \\
-=k_{+1} c_{\mathrm{N}}-k_{-1} c_{\mathrm{R}}-k_{2} c_{\mathrm{R}} \\
t=0, c_{N}=c_{N 0}, c_{R}=0
\end{gathered}
$$

Temperature dependence of the rate constants was expressed in form of a rearranged Arrhenius equation,

$$
k_{i}=e^{\ln k_{i 0}} e^{\left[\left(E_{i} / R T_{0}\right)\left(1-T_{0} / T\right)\right]}, i=+1,-1,2
$$

where $E_{i}$ is the activation energy of the $i$ th reaction, $R$ is the universal gas constant, and $k_{i 0}$ the value of rate constant $k_{i}$ at reference temperature $T_{0}=343.15 \mathrm{~K}$. The so-called multitemperature evaluation (Vrábel et al., 1997; Polakovič and Bryjak, 2002), where inactivation data for all temperatures are fitted simultaneously using non-linear regression, was applied. The mathematical modelling software Athena Visual Workbench (Stewart \& Associates, Madison, WI, U.S.A.) was used for parameter estimation employing a gradient non-linear least square method and parameter uncertainties calculation based on the variance-covariance matrix.

\section{Results and discussion}

Fig. 1 displays the results of batch inactivation experiments of $\beta$-GAL in concentrated lactose solution in the temperature range of $65-75^{\circ} \mathrm{C}$. Fast exponential decline of activity was observed at higher temperatures when the half-life was only $0.5 \mathrm{~min}$ at $75^{\circ} \mathrm{C}$ and $4 \mathrm{~min}$ at $70^{\circ} \mathrm{C}$. At two lower temperature values, biphasic character of inactivation was observed which was strongly pronounced at $65{ }^{\circ} \mathrm{C}$. The half-life at $65^{\circ} \mathrm{C}$ was $75 \mathrm{~min}$ but the enzyme still kept $25 \%$ of its initial activity after 8 hours. These values represent very good thermal stability compared to that of other common $\beta$-galactosidases presented in Introduction. Flaschel (2006) determined the half-life of $A$. oryzae $\beta$-GAL from another source to be $1 \mathrm{~h}$ at $60^{\circ} \mathrm{C}$ but all activity was lost after $4 \mathrm{~h}$ since the inactivation process was governed by first-order kinetics.

In order to evaluate the stabilisation effect of lactose, inactivation was carried out also in a lactose-free buffer (Fig. 2), where the inactivation was evidently faster. The stabilisation effect of the $300 \mathrm{~g} / \mathrm{L}$ lactose 


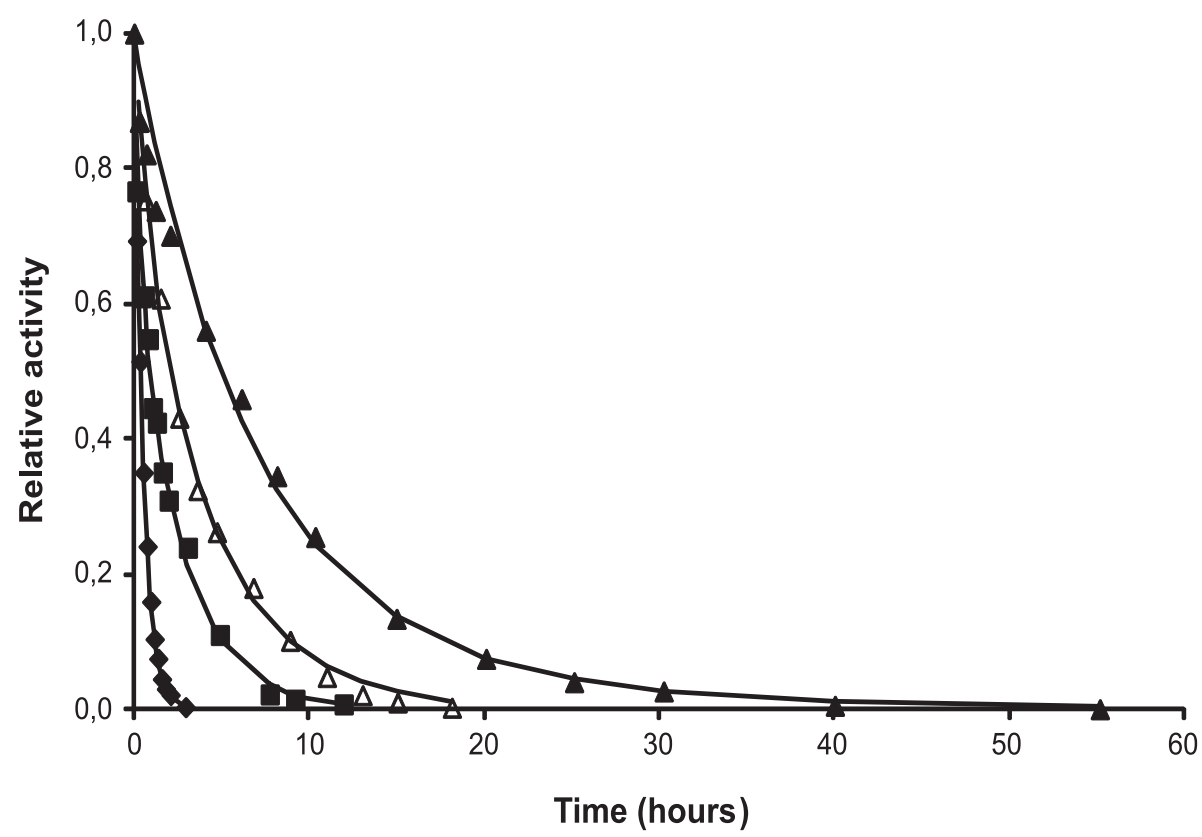

Fig. 1. Thermal inactivation of $\beta$-GAL in a reaction medium with the initial lactose concentration of $300 \mathrm{~g} / \mathrm{L}$. Symbols represent experimental data at individual temperatures: $\bullet-75^{\circ} \mathrm{C}, \mathbf{-}-70^{\circ} \mathrm{C}, \triangle-67.5^{\circ} \mathrm{C}, \boldsymbol{\Delta}-65^{\circ} \mathrm{C}$.

Lines are the fitted activity values using the model specified by Eqs. (1)—(3).

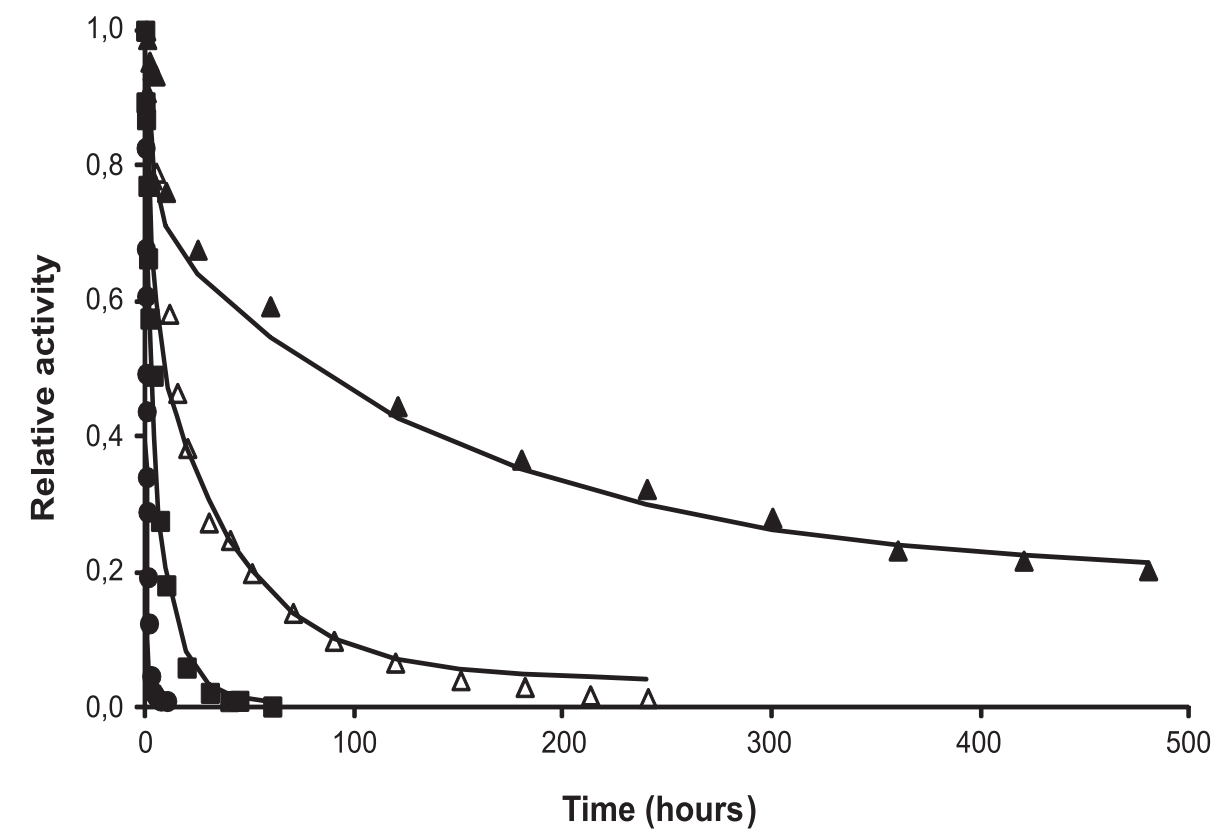

Fig. 2. Thermal inactivation of $\beta$-GAL in lactose-free buffer. The meaning of all symbols and lines is the same as in Fig. 1 except for the experimental data at $72.5^{\circ} \mathrm{C}(\diamond)$.

solution can be estimated to be about $5{ }^{\circ} \mathrm{C}$. This degree of stabilisation is in compliance with the trend of saccharide concentration on enzyme inactivation in our previous study (Madlová et al., 2000).

A stabilisation effect of about $2{ }^{\circ} \mathrm{C}$ was observed for the inactivation of pectin methylesterase in different fruit juices containing about $10-15 \%$ of saccharides (Wilińska et al., 2008).

A much stronger stabilisation effect was observed for fructosyltransferase inactivation in a $700 \mathrm{~g} / \mathrm{L}$ saccharide solution (Onderková et al., 2010).

It was estimated to be from $8{ }^{\circ} \mathrm{C}$ at higher temperatures to $15^{\circ} \mathrm{C}$ at lower temperatures.

Experimental inactivation data were fitted with the model described above in the Mathematical modelling section. Estimated parameter values for the inactivation in the concentrated lactose solution and their $95 \%$ confidence intervals are pre- 
sented in Table 1. Mean square error of the activity values was $2.6 \%$. Fig. 1 demonstrates a good match between the measured and fitted activity values. Unfortunately, activation energy of the backward reaction, $E_{-1}$, could not be estimated reliably. It had to be fixed to get good statistical characteristics of the remaining model parameters. This is a common problem for models based on the Lumry-Eyring mechanism (Polakovič and Bryjak, 2002; Onderková et al., 2010).

The estimated activation energies $E_{1}$ and $E_{2}$ can be compared with the values presented by other authors. Ladero et al. (2006) dealt with the investigation of $K$. fragilis $\beta$-GAL in different solutions. Typical values of activation energy were from $250 \mathrm{~kJ} \mathrm{~mol}^{-1}$ to $400 \mathrm{~kJ} \mathrm{~mol}^{-1}$. Braga et al. (2013) give values from $330 \mathrm{~kJ} \mathrm{~mol}^{-1}$ to $420 \mathrm{~kJ} \mathrm{~mol}^{-1}$ for several $\beta$-GAL preparations from $K$. marxianus. A broad range of activation energy values, from $270 \mathrm{~kJ} \mathrm{~mol}^{-1}$ to $940 \mathrm{~kJ} \mathrm{~mol}^{-1}$, were reported by Flaschel (2006) for $\beta$-GAL from three different microbial sources. The value given for $A$. oryzae $\beta$-GAL, $515 \mathrm{~kJ} \mathrm{~mol}^{-1}$, is essentially the same as that of $E_{2}$ in this work (Table 1).

Tab. 1. Model parameters of $\beta-\mathrm{GAL}$ inactivation kinetics in a reaction medium with the initial lactose concentration of $300 \mathrm{~g} / \mathrm{L}$.

\begin{tabular}{lc}
\hline Parameter & Value $\pm 95 \%$ confidence interval \\
\hline$k_{+10}\left(\mathrm{~min}^{-1}\right)$ & $0.305 \pm 0.034$ \\
$k_{-10}\left(\mathrm{~min}^{-1}\right)$ & $0.127 \pm 0.044$ \\
$k_{20}\left(\mathrm{~min}^{-1}\right)$ & $0.132 \pm 0.062$ \\
$E_{+1}\left(\mathrm{~kJ} \mathrm{~mol}^{-1}\right)$ & $307 \pm 27$ \\
$E_{-1}\left(\mathrm{~kJ} \mathrm{~mol}^{-1}\right)$ & $23 \pm$ n.d. \\
$E_{2}\left(\mathrm{~kJ} \mathrm{~mol}^{-1}\right)$ & $518 \pm 93$ \\
\hline
\end{tabular}

n.d. - not determined.

Since the value of $E_{+1}$ is substantially lower than that of $E_{2}$, temperature will play a significant role in the inactivation rate-controlling steps. Table 1 shows that the reaction rate constants at the reference temperature of $70^{\circ} \mathrm{C}$ are not very different. The equilibrium constant of the first reaction, $K_{1}$, at this temperature is equal to 2.4. The reversible character of the first reaction was thus manifested at this temperature and the dynamics of activity loss was influenced by both steps of the series reaction. Due to the low activation energy of the backward reaction, $E_{-1}$, the dependence of $K_{1}$ on temperature was determined primarily by the value of $E_{+1}$. The equilibrium constant thus increases rather quickly with the temperature and the equilibrium of the first reaction is strongly shifted toward the formation of the inactive inter- mediate R. $K_{1}$ reached the value of 10 at $75^{\circ} \mathrm{C}$ and the first reaction became apparently irreversible. Thus, the first-step is the rate-controlling step at high temperatures.

An opposite trend can be observed when the inactivation process is carried out at lower temperatures. As it has been mentioned above, the activity course at $65{ }^{\circ} \mathrm{C}$ had a bend at the residual activity of about $70 \%$. It can be assumed that the first step approached an apparent equilibrium, which correlates very well with the value of $K_{1}=0.55$. The rate constant $k_{+1}$ was about seven times higher than $k_{2}$. The slower rate of the second phase of inactivation was thus determined primarily by the rate of the second step. To be more precise, the activity course in the second phase can be approximated by the following equation (Gibbs et al., 2005):

$$
a=\frac{e^{-\frac{K_{1} k_{2} t}{K_{1}+1}}}{K_{1}+1}
$$

Experimental lifetime of several hours observed at $65^{\circ} \mathrm{C}$ appears to be acceptable for the use of this enzyme preparation in its soluble form for the production of GOS (Braga et al., 2013; Osman et al., 2014).

It is however worth to emphasize that the significant inactivation during the production process decreases its productivity and total turnover number of the biocatalyst. The effect of temperature on the rate of the GOS synthesis is much weaker compared to that on the inactivation rate. A typical value of activation energy for GOS synthesis by free $\beta$-GAL is $20 \mathrm{~kJ} \mathrm{~mol}^{-1}$ (Osman et al., 2014).

A change of temperature by $5{ }^{\circ} \mathrm{C}$ thus results only in a $10 \%$ change of the GOS synthesis rate. For these reasons, the temperature of $65^{\circ} \mathrm{C}$ may not be the optimal one.

Lower temperatures are necessary if this enzyme was applied in the immobilised form since the immobilisation costs have to be compensated by the repeated or continuous use of the biocatalyst (Urrutia et al., 2013).

Economic benefits of the immobilised $\beta$-GAL operational lifetime of one year or longer were presented a long time ago (Yang and Okos, 1989).

Although many advanced immobilisation methods increase the thermostability of $\beta$-GAL (Urrutia et al., 2013), many common methods based on commercial carriers did not change the enzyme's stability (Giacomini et al., 1998; Adamíková et al., 2018). It is therefore meaningful to use the model obtained for the simulation of $\beta$-GAL performance at temperatures below $65^{\circ} \mathrm{C}$.

High activation energy values of the forward reactions, $E_{+1}$ and $E_{2}$, underscore the fact that the 
$\beta$-GAL inactivation rate should decrease rather strongly at lower temperatures. This effect is even more enhanced by the low activation energy of $E_{-1}$ as it was discussed above. The calculated value of $K_{1}$ was only 0.12 at $60{ }^{\circ} \mathrm{C}$ and 0.005 at $50{ }^{\circ} \mathrm{C}$. The first phase becomes then absent in the inactivation course and Eq. (4) is simplified to

$$
a=e^{-K_{1} k_{2} t}
$$

Thus obtained inactivation curve has the form of a simple exponential relationship but it cannot be considered as first-order kinetics since the exponential parameter is the product of the rate constant $k_{2}$ and equilibrium constant $K_{1}$. The inactivation process is controlled by the rate of the second reaction but this proceeds very slowly because the concentration of intermediate $\mathrm{R}$ is very low.

Eq. (5) can then be used to calculate the $\beta$-GAL half-life $t_{1 / 2}$ at lower temperatures:

$$
t_{1 / 2}=\frac{\ln 2}{K_{1} k_{2}}
$$

As expected, the predicted half-life increases very quickly in the direction toward lower temperatures. At $60^{\circ} \mathrm{C}, t_{1 / 2}$ is 7 days which implies that the activity loss of free enzyme in a batch process lasting several hours has a small effect on the bioreactor productivity and enzyme consumption. The predicted halflife of 580 days at $55^{\circ} \mathrm{C}$ meets the requirement for immobilised $\beta$-GAL. Of course, uncertainty of these predictions is influenced by the problem with the reliability of the estimated value of $E_{-1}$. Nonetheless, the temperature of $55^{\circ} \mathrm{C}$ is a good first estimate for experimental verification of operational temperature of immobilised $\beta$-GAL preparations screened in our recent study (Adamíková et al., 2018).

\section{Conclusions}

This work deals with thermal inactivation of a commercial $\beta$-GAL from $A$. oryzae in a concentrated lactose solution in the temperature range of $65-75^{\circ} \mathrm{C}$. Inactivation experiments in lactose-free buffer showed that a $300 \mathrm{~g} / \mathrm{L}$ lactose solution has a stabilisation effect on $\beta$-GAL. Experimental activity courses were used to suggest a plausible mechanism of inactivation and identify kinetics of the inactivation process in the lactose solution. Since the inactivation course was clearly biphasic at the temperature of $65^{\circ} \mathrm{C}$, a model based on the two-step Lumry-Eyring mechanism was specified. Using the multitemperature method of inactivation data evaluation, a good fit was obtained for this model.

The verified model provided the pre-exponential rate constant and activation energy values to be used to determine the influence of individual rate constants of the two-step reaction mechanism at different temperatures. It can be inferred from them that the first reaction becomes essentially irreversible at temperatures above $75^{\circ} \mathrm{C}$. The inactivation rate is then governed by the rate constant of the first reaction. On the contrary, the model results extrapolated into the region of lower temperatures imply that the inactivation is governed by the second, irreversible, reaction at temperatures below $60{ }^{\circ} \mathrm{C}$. The predicted enzyme half-live increases quickly from the experimental value of 75 minutes at $65^{\circ} \mathrm{C}$ to 7 days at $60{ }^{\circ} \mathrm{C}$ and 580 days at $55^{\circ} \mathrm{C}$. These predictions have been the starting point in our further study on the operational stability of immobilised $\beta$-GAL which is currently under progress.

\section{Acknowledgements}

This work was supported by the Agency of the Ministry of Education, Science, Research and Sport of the Slovak Republic for the Structural Funds of EU (Grant number: ITMS 26240220057).

\section{References}

Adamíková J, Antošová M, Polakovič M (2018) Biotechnol. J.: In press. DOI: 10.1002/biot.201800120.

Braga ARC, Manera AP, Ores JdC, Sala L, Maugeri F, Kalil SJ (2013) Food Technol. Biotechnol. 51: 45-52.

Flaschel E (2006) Eng. Life Sci. 6: 131-138.

Giacomini C, Villarino A, Franco-Fraguas L, BatistaViera F (1998) J. Mol. Catal. B 4: 313-327.

Gibbs PR, Uehara CS, Neunert U, Bommarius AS (2005) Biotechnol. Prog. 21: 762-774.

Illeová V, Polakovič M, Štefuca V, Ačai P, Juma M (2003) J. Biotechnol. 105: 235-243.

Ladero M, Ferrero R, Vian A, Santos A, Garcia-Ochoa F (2005) Enzyme Microb. Technol. 37: 505-513.

Ladero M, Ruiz G, Pessela BCC, Vian A, Santos A, Garcia-Ochoa F (2006) Biochem. Eng. J. 31: 14-24.

Ladero M, Santos A, Garcia-Ochoa F (2006) Enzyme Microb. Technol. 38: 1-9.

Lumry R, Eyring H (1954) J. Phys. Chem. 58: 110-120.

Madlová A, Antošová M, Polakovič M, Báleš V (2000) Chem. Pap. 54: 339-344.

Nakanishi K, Matsuno R, Torii K, Yamamoto K, Kamikubo T (1983) Enzyme Microb. Technol. 5: 115-120.

Onderková Z, Bryjak J, Vaňková K, Polakovič M (2010) Enzyme Microb. Technol. 47: 134-139.

Osman A, Symeou S, Trisse V, Watson KA, Tzortzis G, Charalampopoulos D (2014) Biochem. Eng. J. 82: 188-199.

Polakovič M, Bryjak J (2002) J. Mol. Catal. B 19-20: 443-450.

Urrutia P, Mateo C, Guisan JM, Wilson L, Illanes A (2013) Biochem. Eng. J. 77: 41-48.

Vrábel P, Polakovič M, Štefuca V, Báleš V (1997) Enzyme Microb. Technol. 20: 348-354.

Wilińska A, de Figueiredo Rodrigues AS, Bryjak J, Polakovič M (2008) J. Food Eng. 85: 459-465.

Yang ST, Okos MR (1989) Biotechnol. Bioeng. 33: 873-885. 